\title{
COGNITION ENHANCEMENT USING VIRTUAL REALITY IN APARTMENT CUSTOMIZATION
}

\author{
Amit Dayan ${ }^{1}$ and Rafael Sacks ${ }^{2}$
}

\begin{abstract}
The design and construction of customer configured apartments is challenging when customers are unable to interpret construction drawings or lack the knowledge or competence to deliver the decisions and information that is required from them. Builders dedicate significant managerial and technological effort to manage the customization process with their customers, and this process is commonly recognized to be inefficient. Studies suggest that one root cause is the fact that most customers are not construction professionals, hence decision making is often a challenging and sometimes unpleasant task for them due to insufficient product cognition. In this study we developed a virtual reality tool for the facilitation of an immersive presentation of yet to be built apartments to customers, speculating that cognition may be enhanced and facilitate the customization decisions. An experiment was conducted to identify and measure cognition differences. Some areas of measured cognition shown noticeable improvement which imply for significant cognition enhancement. Exploitation of the findings by future adoption of the examined method is discussed and suggested to construction companies.
\end{abstract}

Keywords: Product customization, Apartment design changes, Virtual Reality, Residential construction.

\section{INTRODUCTION}

The building construction industry's operations have traditionally been divided into residential, commercial and other sub-sectors, as each of them has served different clients with different needs and hence developed different market norms, managerial approaches and supporting operations.

Among many aspects differentiating the sub-sectors is the degree of customization offered to the purchaser of the built product. Office spaces are traditionally built according to highly specific demands. High end and luxury housing must appeal to their specific target market and hence also offer customers high levels of customization. Standard housing, on the other hand, is often considered a 'mass produced' constructed product and until recently offered little or no customization options.

Emerging competition in many markets has forced construction companies to consider new ways for delivering value to their potential customers. Among the new services offered is the option to customize the purchased dwelling; customization extends from minor customization, such as selecting among various offered floor/wall covers, to more significant customization, such as altering the locations of partitions or tailoring a customized kitchen. Today, the possibility to customize a newly purchased apartment is

1 Graduate Student, Faculty of Civil and Environmental Engineering, Technion - Israel Institute of Technology, Haifa, Israel. amitda@campus.technion.ac.il

2 Associate Professor, Faculty of Civil and Environmental Engineering, Technion - Israel Institute of Technology, Haifa, Israel, cvsacks@techunix.technion.ac.il 
among the important factors customers consider when looking to buy an apartment (Frutos and Borenstein 2004).

Advances in information technologies, manufacturing (construction methods) and management methods has made 'Mass Customization' a reality (Herd et al. 2009) in other verticals, and construction companies inevitably followed the trend as a business response in saturated markets. Mass customization consists of combining the efficiency of mass production with the differentiation possibilities of customization, creating variety through flexibility and quick responsiveness (Pine 1993). Customization of dwellings has become a mandatory requirement in a large portion of the residential construction sector (Rocha 2011).

The process of eliciting customization requirements from large numbers of customers and implementing them in the field poses significant challenges to construction companies as the process revolves around information that has to be obtained, analysed, represented, stored, shared, reviewed, approved and delivered for procurement and construction. As quantities of information grew larger IT solutions were a natural step and these were noted to have positive impact on the operations and productivity of the customization and construction process (Frutos and Borenstein 2004). Databases, electronic communication and computer aided drawings have become commonplace.

However, studies indicate that the customization process still suffers major inefficiencies that are characteristic of other fields: customers failing to deliver information or decisions on time, customers requesting changes after construction has been done, higher than expected overhead costs to facilitate the customization process by the constructing company, customers altering their decisions multiple times prior to construction (Sacks and Goldin 2007) and generally poor customer satisfaction. The waste is not limited to customer experience, operational efficiency and construction costs; as rework and reconstruction of the interiors are often the solution in the existing state, unnecessary environmental waste and emissions are also generated (Lee and Ha 2013).

Parallel retail studies indicate that poor levels of satisfaction may be attributed to the overwhelming number of choices required from the customer during the process (Chin and Smithwick 2009). Garbarino and Edell (1997) further indicated that "...when products are complex or consumers have little knowledge, the categorization process becomes more difficult, leading to the generation of greater negative affect". Cognition and cognitive learning are often referenced in the field of customized products. Cognition encompasses the mental process of understanding, evaluating, planning, deciding, and thinking (Peter and Olson 2004).

Looking for the root causes of the aforementioned symptoms leads to examination of parallel industries where customer input is required for final realization of a product. Although the products are different, similarities in the customization process indicate the main causes for operational drawbacks:

1. As the degree of technical complexity rises, lack of clarity emerges and the number of choices grows - a customer with no relevant professional background may experience decreased satisfaction, affect or even discomfort with the process/product (Greifeneder et al. 2010).

2. Inadequate cognition among customers may delay decision making and decrease affect. Since "customer satisfaction acts as a mediator between pre-exposure and postexposure attitudes" (LaBarbera and Mazursky 1983), decreased satisfaction is also predicted.

The term 'Need for Cognition' (NFC) was coined by psychologists in the mid-twentieth century, and Cacioppo and Petty (1982) developed an NFC rank scale. The scale rated the 
extents to which an individual tends to engage in and enjoy effortful cognitive activities (Petty et al. 2009). NFC was further studied in the field of consumerism research as Mantel and Kardes (1999) suggested that 'it appears that involvement only motivates more analytical thought and consideration of the information available.' This finding is expressed in the apartment customization market as supplying the customer with relatively vast amounts of information and alternatives to consider as an inherent part of the process. Differences in the comparison depth and quality among different customers are expected according to each person's NFC.

In spite of the acknowledged understanding that customers' product cognition is of major value to the process, little has been done to foster technology advancements to support the industry's efforts in this field. Since the adoption of CAD (computer aided drawing) tools, no major technological tool is noted to be widely adopted for supporting dwellers in the process of customizing their purchased apartment. This fact raises questions as relevant interaction and visualization tools have made significant progress in recent times such as: web based design/sketching, 3D imaging, supplier's online information, augmented and virtual reality (VR). Among the few examples, Zhang et al. (2014) introduced a VR application supporting apartment customization, though focused on the technological aspects of generating, storing and sharing the modelled information, without addressing or measuring the 'human related' influences of utilizing such a tool.

$3 \mathrm{D}$ visuals, including VR, have been used in industry to support demonstration and cognitive processes mostly for marketing, instructional and reviewing needs (Mahdjoubi et al 2014, Fu and East 1999, Gallagher et al 2005). It may be assumed that similar benefits may be achieved by applying such techniques to the residential development sector.

This study focused on the area of the customer's cognition and sought opportunities for improvement in the form of cognition enhancement by using 3D imaging-virtual reality tools. This paper begins by explaining the general experimental approach for testing the utility of VR to enhance customer cognition, continues with details of the experiment conducted, and closes with discussion of the implied conclusions and future opportunities.

\section{RESEARCH APPROACH AND METHODS}

\subsection{Approach}

The main research question was: Will a significant difference be recorded in cognition achieved by customers who use virtual reality tools to experience an apartment compared to other customers who experience the same space using tradition drawings only?

The approach is experimental: it relays on creating two controlled focus groups, each consisting of subjects who are encouraged to achieve the highest cognitive learning possible of the same apartment in comparable conditions. The first group is intended to serve as an untreated control group. The second, the experimental group, was introduced to a virtual reality tour in a virtual model of the apartment. As exposure to learning means is comparable, a specific measurement of cognition achieved was developed.

\subsection{Method}

The study was based on actual apartment plans, provided courtesy of a local construction company, and included architectural, sanitary and electrical drawings of a specific fourbedroom apartment. Examples of the drawings are shown in Figure 1. 

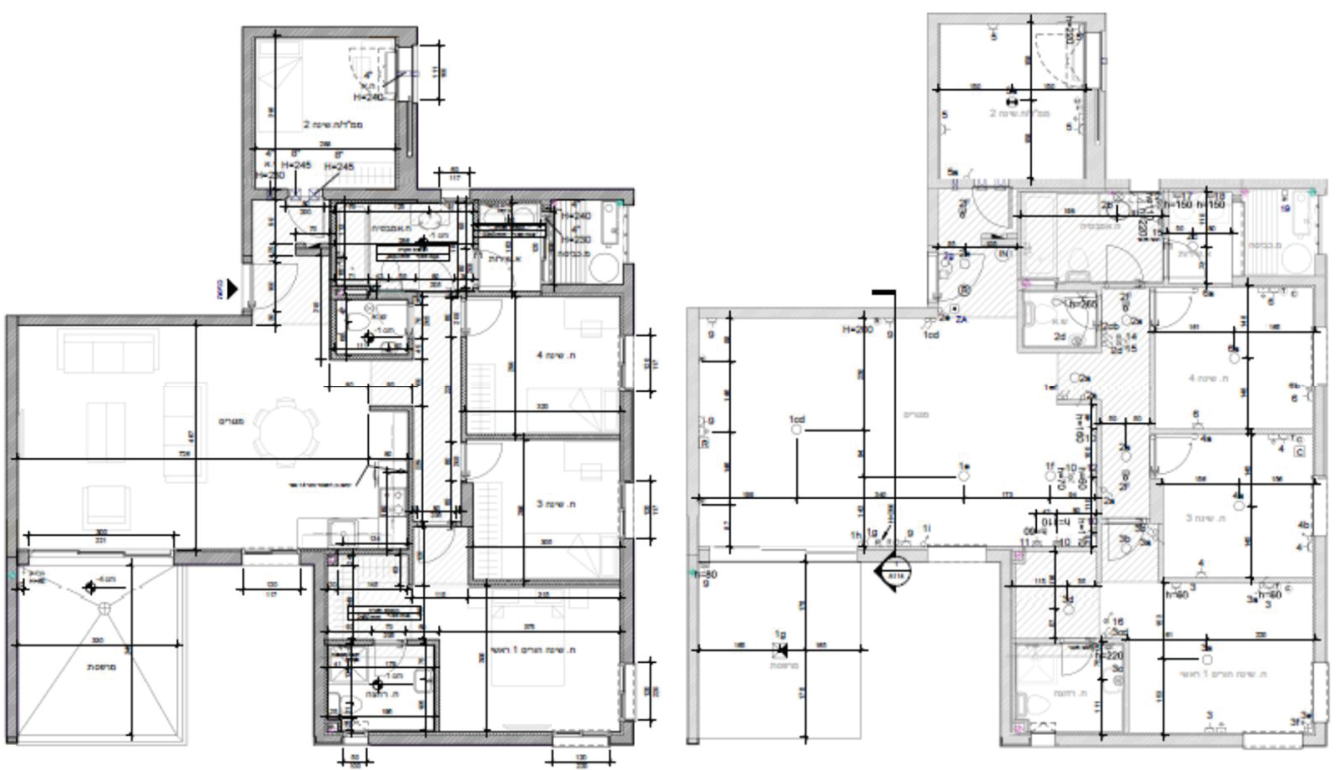

Figure 1: Architectural and electrical plans of the apartment.

The dwelling was originally designed using BIM tools. The original design model was enhanced using 'Revit', adding extra detail and visualization information. Among the visualizations added to the model were: suggested 3D furniture, running dimension lines in the 3D environment, room labels (stamped on doors) and general adaptation of the elements used in the design model to facilitate visualization in a 3D environment.

The Revit model was exported to Unity in order to facilitate a user interface for viewing the model using an 'Oculus Rift' VR headset (as seen in Figure 2). The user interface included walking, object collision, door opening behaviour, view tracing, etc.

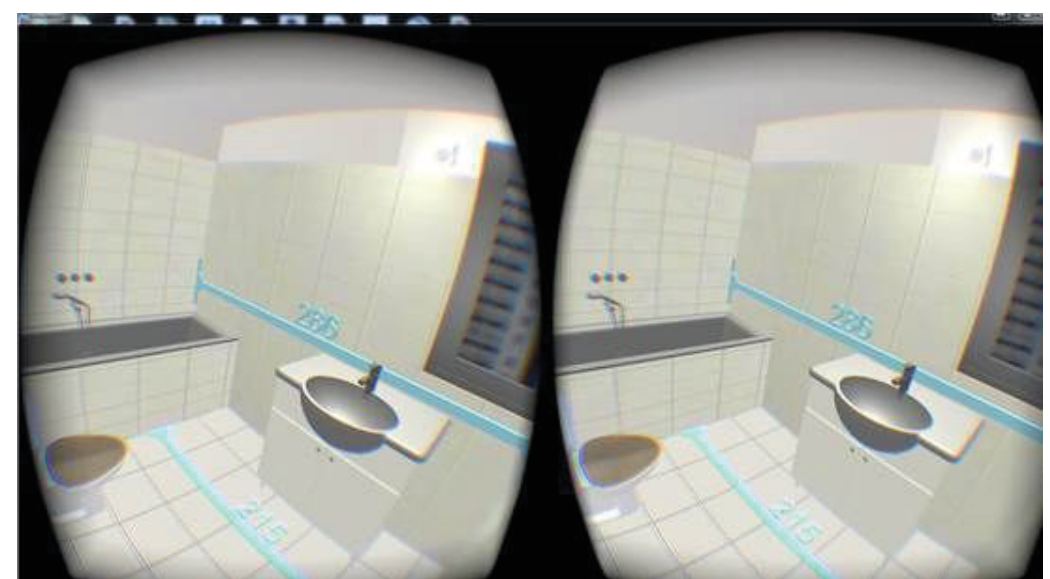

Figure 2: Added information objects in the immersive 3D model.

The Oculus Rift headset was selected as a mean of immersive VR experience. It is noted that other less immersive VR platforms exist (such as VR rooms) that may generate different effects that wasn't measured as part of this experiment. A secondary assessment tool was needed to measure cognition, since direct measurement is not possible using conventional means. A questionnaire was developed that included questions aiming at two major cognition fields: apartment functionality assessment and apartment space/dimensional assessment. The subjects were asked to quantifiably assess aspects and features about the dwelling, asked after the exposure to the examined learning material (drawings/VR), when it was no longer available. 
In order to provoke thought about the apparent use of the dwelling, the questions referred, among other aspects, to subjective assessment of everyday functionality such as: 'how fit is the presented kitchen to your desired use?'. Each of those questions was followed by another question of 'how certain and precise was your judgment in the former question?' and required answers on a defined scale of 1-7. Other questions referred to objective data, such as 'how many light switches do you recall located in the main hallway?', for which answers can be checked against the actual design. Summary questions approached the research question in an unmediated way and asked the participants to evaluate whether and to what degree the use of virtual reality contributed to their perception of the apartment's spaces and functionality.

Bias was controlled by segmentation of the subjects by age groups, professional field, and any possible previous experience with customizing an apartment. Participants were screened to exclude any with construction expertise. Participants had no prior experience with reading construction drawings, and little or no experience using VR.

Subjects were guided to a fair 'common ground' regarding familiarity with the apartment: each participant was guided through the same ritual virtual tour in the apartment, and asked to describe behavioural patterns for different scenarios. The tour was facilitated using the paper drawings and subjects were accompanied by a research facilitator. All participants were given equal time. The control group experienced the virtual tour using the $2 \mathrm{D}$ paper drawings only, while the treatment group experienced the same tour using the same drawings and 3D virtual reality on the Oculus Rift device. Each participant was asked to fill the questionnaire right after finishing the virtual tour.

Mean and variance values were calculated for the examined groups. T-Tests were conducted in order to examine significance of difference between the groups.

\section{FINDINGS, ANALYSIS AND DISCUSSION}

38 subjects participated in the study. Participants were mostly university students and/or their spouses, and all were aged 20-35 years old. Table 1 summarizes the results.

Statistical analysis of the questionnaires revealed the following results:

- Cognition assessment measures addressing dimensional and space perception all recorded higher means in the virtual reality group compared to the control subjects. $\mathrm{P}$-values for significance analysis ranged within $0.1 \%$ to $5 \%$ among the question.

- Cognition assessment measures addressing functionality perception also recorded higher mean values in the VR group, though with higher calculated variance in some of the measures. P-values ranged from $0.1 \%$ in the more significant measures to $46 \%$ in others.

- Cognition assessment measures addressing quantity oriented memory of the dwelling recorded higher accuracy (smaller deviation) within the VR group.

- Subjects required to rate the extent to which they experienced helpful assistance by the tools allocated to them (drawings/VR) also rated a higher mean value in the VR group with a P-value of $0.5 \%$. 
Table 1: Summary of the results

\begin{tabular}{|c|c|c|c|c|c|c|}
\hline Question & Mean & $\begin{array}{l}\text { Mean } \\
\text { (Dwgs) }\end{array}$ & $\begin{array}{c}\text { Mean } \\
(\mathrm{VR})\end{array}$ & $\begin{array}{l}\text { Variance } \\
\text { (Dwgs) }\end{array}$ & $\begin{array}{c}\mathrm{T} \\
\text { value }\end{array}$ & $\begin{array}{c}\mathrm{P} \\
\text { value }\end{array}$ \\
\hline $\begin{array}{l}\text { How easy was the task of evaluating the suitability of } \\
\text { the bedrooms for use by two children? }\end{array}$ & 4.9 & 4.5 & 5.4 & 1.2 & 3.19 & 0.00 \\
\hline How clear/known to you are the room's precise areas? & 4.3 & 3.8 & 4.8 & 2.7 & 1.68 & 0.06 \\
\hline $\begin{array}{l}\text { Estimate how many people can sit comfortably in the } \\
\text { dining area }\end{array}$ & 5.7 & 5.8 & 5.6 & 1.7 & $\mathrm{~N} / \mathrm{A}$ & 0.50 \\
\hline $\begin{array}{l}\text { How confident are you regarding precision of your } \\
\text { answer to the former question? }\end{array}$ & 4.3 & 4.3 & 4.4 & 2.2 & 0.10 & 0.46 \\
\hline $\begin{array}{l}\text { Estimate how many footsteps will it take to get from the } \\
\text { parents' washroom door to the apartment's front door }\end{array}$ & 15.1 & 15.5 & 14.6 & 40.7 & N/A & 0.50 \\
\hline $\begin{array}{l}\text { How sure are you of the accuracy of your answer to the } \\
\text { last question? }\end{array}$ & 3.6 & 3.0 & 4.3 & 1.9 & 2.92 & 0.01 \\
\hline $\begin{array}{l}\text { Estimate how many people can comfortably stand in the } \\
\text { laundry room? }\end{array}$ & 2.1 & 1.9 & 2.2 & 0.2 & $\mathrm{~N} / \mathrm{A}$ & 0.50 \\
\hline $\begin{array}{l}\text { How sure are you of the accuracy of your answer to the } \\
\text { last question? }\end{array}$ & 5.1 & 4.6 & 5.5 & 1.7 & 2.43 & 0.01 \\
\hline $\begin{array}{l}\text { What is the best TV installation height to allow } \\
\text { comfortable watching in the parents' bedroom? }\end{array}$ & 126.6 & 123.9 & 129.2 & 2490.5 & N/A & 0.50 \\
\hline $\begin{array}{c}\text { How sure are you of the accuracy of your answer to the } \\
\text { last question? }\end{array}$ & 3.4 & 2.9 & 3.9 & 2.1 & 2.01 & 0.03 \\
\hline $\begin{array}{l}\text { How easily and precisely can you estimate the distance } \\
\text { from the living room sofa to the TV screen? }\end{array}$ & 4.6 & 4.1 & 5.1 & 1.3 & 3.60 & 0.00 \\
\hline $\begin{array}{l}\text { How easily and precisely can you estimate the available } \\
\text { storage volume in the walk in closet? }\end{array}$ & 3.0 & 2.4 & 3.6 & 1.0 & 5.38 & 0.00 \\
\hline $\begin{array}{c}\text { At what height are most electrical outlets installed in } \\
\text { the apartment? }\end{array}$ & 74.6 & 100.0 & 72.5 & N/A & N/A & 0.50 \\
\hline $\begin{array}{l}\text { How many light switches are installed in the } \\
\text { apartment's corridor? }\end{array}$ & 3.0 & 3.2 & 2.9 & 15.7 & $\mathrm{~N} / \mathrm{A}$ & 0.50 \\
\hline $\begin{array}{c}\text { Estimate how long will it take for regular cleaning of } \\
\text { the apartment on a weekly basis }\end{array}$ & 3.9 & 3.6 & 4.2 & 2.6 & N/A & 0.50 \\
\hline $\begin{array}{l}\text { How sure are you of the accuracy of your answer to the } \\
\text { last question? }\end{array}$ & 4.8 & 4.6 & 4.9 & 1.6 & 0.73 & 0.24 \\
\hline $\begin{array}{c}\text { In your opinion - how well is the kitchen suited for your } \\
\text { personal needs? }\end{array}$ & 4.7 & 4.9 & 4.5 & 1.9 & N/A & 0.50 \\
\hline $\begin{array}{l}\text { How sure are you regarding your answer to the former } \\
\text { question? }\end{array}$ & 5.3 & 4.7 & 5.9 & 3.7 & 1.44 & 0.08 \\
\hline $\begin{array}{l}\text { To what extent did you feel that the VR/drawing } \\
\text { (accordingly) helped you form a clear understanding of } \\
\text { the apartment's spaces, areas and dimensions? }\end{array}$ & 4.9 & 4.1 & 5.8 & 1.7 & 4.44 & 0.00 \\
\hline $\begin{array}{l}\text { To what extent did you feel that the VR/drawing } \\
\text { (accordingly) helped you depict a clear understanding of } \\
\text { the apartment's functionalities and possible everyday } \\
\text { uses? }\end{array}$ & 5.1 & 4.4 & 5.7 & 1.9 & 2.86 & 0.01 \\
\hline
\end{tabular}

The described findings strongly imply that significant cognitive enhancement was obtained by utilizing virtual reality as a thought provoking demonstration tool. Actual value may be generated in the process of apartment customization on two fronts: customers and the construction companies. Customers currently face "the paradox of 
choice" when approaching the design of a new apartment: the vast scope of choices require customers to spend hours learning their options within the scope of available choices and deciding among them. Testimonies state that a typical net time frame for customers to engage in the customization task may range between 15-200 hours per dwelling. Furthermore, the time investment is not guaranteed to correlate with actual satisfaction at the end of the process due to the inherent uncertainty within it. The utilization of VR presents an opportunity to improve customer satisfaction by establishing certainty and shortening the process.

Construction companies may pursue even more direct benefit goals. As the customization overhead cost component of a project is directly influenced by the time frame needed to serve customers to facilitate the customization process, personnel savings may be predicted. Reducing the amount of post-construction changes may support enhanced flow of the actual works on site and reduce the need for tight revision management of customization drawings and information.

It is likely that customer value and satisfaction may also play a role in the adoption of VR tools. As competition continues to emerge one might expect that early adopters among construction companies may achieve a differentiating service in the market and establish a competitive edge. The extent to which customers report positive experiences may influence the rest of the market.

\section{CONCLUSIONS}

The findings imply significant cognition enhancement attributed to the use of virtual reality for perception of an apartment, its function and its proportions compared to the use of traditional drawings and CAD. We note, however, that whereas this study involved participants of initial low cognitive learning state (the apartments were first presented to them during the experiment), actual apartment customers address the customization process from a more advanced cognitive learning state. Further research is therefore required in order to evaluate the cognition enhancement experienced by participants of the latter type.

Nevertheless, as this kind of enhancement becomes recognized as useful, pressure for exploiting the described technologies may increase. Use may not be limited to the customization of dwellings, as similar difficulties are experienced in parallel sub-sectors such as offices and commercial spaces.

\section{ACKNOWLEDGMENT}

The authors thank Tidhar Group for their kind support and participation in this study, and in particular, Mr. Banderski, Mr. Bagim, Ms. Ezra and Ms. Horesh. We also acknowledge the contributions of Mr. Yosef and Ms. Ben Alon of the Technion's virtual construction lab.

\section{REFERENCES}

Benros, D., Duarte, J.P., 2009. An integrated system for providing mass customized housing. Autom. Constr. 18, 310-320. doi:10.1016/j.autcon.2008.09.006

Cacioppo, J.T., Petty, R.E., 1982. The need for cognition. J. Pers. Soc. Psychol. 42, 116-131. doi:10.1037/0022-3514.42.1.116 
Chin, R., Smithwick, D., 2009. Environmental impacts of utilizing mass customization: energy and material use of mass customization vs. mass production, in: 5th World Conference on Mass Customization \& Personalization, Helsinki, Finland.

Fu, M. C., and East, E. W. (1999). The Virtual Design Review. Computer-Aided Civil and Infrastructure Engineering, 14(1), 25-35.

Frutos, J.D., Borenstein, D., 2004. A framework to support customer-company interaction in mass customization environments. Comput. Ind. 54, 115-135. doi:10.1016/j.compind.2003.09.004

Gallagher, A. G., Ritter, E. M., Champion, H., Higgins, G., Fried, M. P., Moses, G., Smith, C. D., and Satava, R. M. (2005). Virtual Reality Simulation for the Operating Room: Proficiency-Based Training as a Paradigm Shift in Surgical Skills Training. Annals of Surgery, 241(2), 364-372.

Garbarino, E.C., Edell, J.A., 1997. Cognitive effort, affect, and choice. J. Consum. Res. 24, 147-158.

Greifeneder, R., Scheibehenne, B., Kleber, N., 2010. Less may be more when choosing is difficult: Choice complexity and too much choice. Acta Psychol. (Amst.) 133, 45-50. doi:10.1016/j.actpsy.2009.08.005

Herd, K., Bardill, A., Karamanoglu, M., 2009. 2.2 The Co-Design Experience: Conceptual Models and Design Tools for Mass Customization. Res. Mass Cust. Pers. Strateg. Concepts-Appl. Cases 181.

LaBarbera, P.A., Mazursky, D., 1983. A Longitudinal Assessment of Consumer Satisfaction/Dissatisfaction: The Dynamic Aspect of the Cognitive Process. J. Mark. Res. 20, 393. doi: $10.2307 / 3151443$

Lee, S., Ha, M., 2013. Customer interactive building information modeling for apartment unit design. Autom. Constr. 35, 424-430. doi:10.1016/j.autcon.2013.05.026

Mahdjoubi, L., Hao Koh, J., and Moobela, C. (2014). "Effects of Interactive Real-Time Simulations and Humanoid Avatars on Consumers' Responses in Online House Products Marketing." Computer-Aided Civil and Infrastructure Engineering, 29(1), 31-46.

Mantel, S.P., Kardes, F.R., 1999. The Role of Direction of Comparison, Attribute-Based Processing, and Attitude-Based Processing in Consumer Preference. J. Consum. Res. 25, 335-352. doi:10.1086/209543

Peter, J.P., Olson, J., 2004. Consumer Behavior and Marketing Strategy. Mcgraw-Hill, New York.

Petty, R.E., Briñol, P., Loersch, C., McCaslin, M.J., 2009. The need for cognition. Handb. Individ. Differ. Soc. Behav. 318-329.

Pine, B.J., 1993. Mass Customization: The New Frontier in Business Competition. Harvard Business Press.

Rocha, C.G. da, 2011. A conceptual framework for defining customisation strategies in the house-building sector. Universidade Fed. Rio Gd. Sul Esc. Eng. Programa Pós-grad. Em Eng. Civ.

Sacks, R., Goldin, M., 2007. Lean Management Model for Construction of High-Rise Apartment Buildings. J. Constr. Eng. Manag. 133, 374-384. doi:10.1061/(ASCE)07339364(2007)133:5(374)

Zhang, M., Pan, Z., Huang, X., Xiang, N., Wang, S., Zhu, P., 2014. EasyHome: an online virtual home decoration system. Comput. Animat. Virtual Worlds 25, 101-113. doi:10.1002/cav.1549 